\title{
INTERAKSI ANTARMANUSIA MELALUI MEDIA SOSIAL FACEBOOK MENGENAI TOPIK KEAGAMAAN
}

\author{
Benedictus A. Simangunsong \\ Program Studi Ilmu Komunikasi \\ Universitas Pelita Harapan UPH Boulevard, Karawaci, Gedung E Lantai 15, Telp : 021- \\ 5460901, Ext : 2749. No. Hp : 0818788992. \\ Email : beni2901@yahoo.com
}

\begin{abstract}
Human interaction has shifted with the advent of new media, the internet, especially with the presence of social media. The keyword of social media is a medium intended to share among individuals in order to achieve a better quality of life. The resarch aims finding human interaction trend influenced by social media i.e. Facebook, by looking at the content of the message delivered in sensitive issues phenomena, such as religious belief. Data analysis has been done through descriptive qualitative based on Martin Buber. These result indicates that interaction model can be established if the content of the message delivered in accordance with the wishes of communication, often obtained a description of the interaction that can be done by users against other users so that the purpose of the use of social media can be achieved.
\end{abstract}

Keywords: facebook, Quality of life, interaction, literature, religious phenomena, politics

\begin{abstract}
Abstrak
Interaksi antarmanusia mengalami pergeseran dengan munculnya media baru, internet, khususnya dengan keberadaan media sosial. Kata kunci dari sebuah media sosial adalah sebuah medium yang ditujukan untuk berbagi antara sesama individu dalam rangka untuk mencapai sebuah kualitas kehidupan yang lebih baik (Quality of life). Penelitian ini bertujuan menemukan kecenderungan interaksi antarmanusia yang dipengaruhi oleh media sosial facebook. Metode penelitian dilakukan secara kualitatif dengan teknik pengumpulan data observasi terhadap interaksi yang terjadi antarpengguna melalui media sosial Facebook, dengan melihat pada isi pesan yang disampaikan pada fenomena-fenomena yang sensitif pada kehidupan masyarakat, seperti fenomena tentang kasus keyakinan keagamaan. Analisis data dilakukan secara deskriptif kualitatif analisis literature Martin Buber. Hasil penelitian ini menunjukkan bahwa model interaksi dapat terjalin dengan baik apabila isi dari pesan yang disampaikan sesuai dengan keinginan komunikasi, bahkan sering diperoleh gambaran mengenai interaksi yang bisa dilakukan oleh pengguna terhadap pengguna lainnya sehingga tujuan dari penggunaan media sosial dapat tercapai.
\end{abstract}

Kata Kunci: facebook, Quality of life, interaksi, fenomena keagamaan

\section{Pendahuluan}

Fenomena penggunaan media sosial untuk berbagai macam aktivitas baik secara individual maupun secara berkelompok semakin menunjukkan bermanfaatnya media sosial untuk digunakan dalam berhubungan antar manusia. Ketika terjadi kompetisi dalam bidang politik, penggunaan media sosial menjadi semakin massif dan seringkali individu menilai semakin mengarah pada degradasi individu sebagai pribadi. Banyak individu saling menyerang, menuduh, melakukan stereotypes, bahkan mengganggap etnis dan agamanyalah yang paling unggul dibandingkan dengan lainnya. Kondisi ini menunjukkan bagaimana komunikasi antarpribadi (interpersonal) yang tujuannya adalah berkawan menjadi tergeser menuju hubungan yang sifatnya adalah I-it menurut Martin Buber. 
Penelitain ini bertujuan menemukan model interaksi antarmanusia melalui media sosial facebook (studi kasus pembicaraan mengenai topik keagamaan). Konteks hubungan tidak lagi dalam konteks I-Thou, tetapi sudah menjadi I-it. Penelusuran mengenai pergeseran hubungan ini dilihat dari percakapan yang dilakukan di ruang virtual, khususnya pada penggunaan media sosial Facebook melalui fenomena yang menarik perhatian dari publik khususnya yang menyangkut aktivitas yang berkaitan dengan politik dan keagamaan. Melalui metode studi literatur penulis mencoba mengombinasikannya dengan fenomena yang diambil dari pengguna yang ada dalam satu sistem yang sama dengan penulis. Pengetahuan tentang percakapan yang terjadi di media sosial, apabila tergambarkan secara negatif, maka bisa didorong ke arah perbaikan dan solusi. Sedangkan apabila tergambarkan secara positif, maka bisa didorong untuk memperkuatnya. Adapun tulisan ini fokus pada konsep yang digunakan oleh Martin Buber I-Thou, kemudian penggunaan konsep Interpersonal Mediated Communication dengan penekanan pada pemikiran Sherry Turkle mengenai kekuataan berbicara (The Power of Talk) di era digital.

\section{Pemikiran Martin Buber dalam Era Digital}

Buber secara provokatif mengatakan bahwa sebuah komunikasi antar manusia berada dalam sebuah rentang impersonal sampai interpersonal. Buber alih-alih menekankan interpersonal dalam bentuk kuantitatif, Buber menekankan pemahaman mengenai interpersonal dalam bentuk kualitatif. Dalam bentuk interpersonal, maka penekanannya adalah komunikasi yang terjadi antara paling tidak dua orang, namun bentuknya tidak tepat apabila terkait dengan konsep yang dinyatakan oleh John Stewart dalam bukunya Bridges Not Walls yakni 'Quality of life'. Pemikiran Stewart menekankan interpersonal seperti yang dinyatakan oleh Buber yakni dalam bentuk kualitatif, yakni bagaimana suatu hubungan itu bergerak meningkat atau dengan kata lain menganggap individu sebagai manusia yang unik dan khusus.

Buber seperti dikutip oleh Adler \& Proctor (2012:13), menyatakan bahwa I-It dan I-Thou mewakili 2 cara dimana manusia berhubungan dengan orang lain. Hubungan I-It merupakan suatu hubungan yang berkaitan dengan orang karena mereka dapat melakukan segala sesuatu untuk kita, seperti tertawa atas 'joke' yang kita lontarkan, membeli barang yang dijual. Dari contoh tersebut Buber mencoba menekankan bahwa Hubungan I-It merupakan hubungan yang ada pada sebuah hubungan yang sifatnya personal. Hubungan personal adalah sebuah hubungan yang hanya memiliki makna personal (personal meaning) atau dalam pemikiran teoritisi yang mengajukan Teori Coordinated Management of Meaning (CMM) sebagai sebuah makna yang didapatkan ketika seseorang berinterakso dengan orang lain dan hanya membantu orang untuk menggali informasi baik mengenai diri sendiri maupun orang lain sebagai lawan bicara kita.

Berbeda dengan I-It, maka pada konsep I-Thou, Buber menggambarkannya sebagai cara berinteraksi (way of interacting). 
Penekanan pada konsep I-Thou adalah unik atau dengan kata lain kita bertemu dengan seorang sebagai pribadi, bukan sebagai anggota suatu kategori. Sebagai pribadi artinya Buber ingin menekankan bahwa individu bersifat dinamis, berbeda dari satu waktu ke waktu lain, terus berubah dari satu kejadian ke kejadian lainnya. Kondisi ini sesuai dengan pernyataan dari teoritisi CMM sebagai mendapatkan makna interpersonal, yakni sebuah makna yang dikonstruksikan bersama (co-constructed) oleh partisipan dalam sebuah percakapan atau dengan kata lain kedua belah pihak dalam percakapan menyetujui interpretasi satu sama lain dalam sebuah interaksi.

Lalu bagaimana bila konsep I-Thou atau I-It diterapkan dalam era digital, apakah diperlukan metode yang baru dalam memberikan penilaian mengenai hal tersebut. Misalnya saja apabila si pengguna media sosial Facebook dan individu mempunyai daftar teman, bisakah dinilai mereka sebagai teman yang impersonal atau I-It atau interpersonal atau I-Thou ? Kemudian, bagaimana individu menilai sebuah percakapan dapat memberikan suatu hubungan yang I-Thou sehingga bisa diberikan penilaian yang tepat bahwa I-It dapat dikatakan sebagai suatu percakapan yang menyenangkan diri sendiri, sesuai dengan keinginan diri dan tanpa mempedulikan kepentingan orang lain dan sebaliknya dengan I-Thou, fokus pada makna bersama sehingga percakapan yang terjadi adalah bentuk percakapan yang mendorong terjadinya kesamaan makna ataupun keinginan untuk meningkatkan hubungan yang lebih baik atau positif.

\section{Metode Penelitian}

Dalam penelitian ini dibahas konsep ruang virtual (virtual space). Secara harafiah dapat dikatakan sebagai sebuah ruang tempat penyimpanan data di internet. Konsep ruang virtual dikatakan sebagai cyberspace, maka pemahaman dari ruang virtual adalah ruang aktivitas manusia tanpa batas. Terjadi peralihan tempat aktivitas manusia yang awalnya dibatasi oleh batas geografis maupun bataskeberadaan manusia secara langsung diganti dengan ketiadaan batas secara geografis maupun keberadaan manusia melalui medium. Sehingga seringkali individu tidak mengetahui siapa lawan bicaranya, sehingga konsep ruang virtual dalam hal ini bisa dikatakan dalam terminology 'mediated communication'.

Mediated communication adalah sebuah terminologi yang merujuk pada setiap situasi dimana keberadaan teknologi adalah sebagai sebuah medium yang menginisiasi interaksi tatap muka. Keberadaan ruang virtual berkembang mulai dari ruang yang hanya mengandalkan produsen sebagai komunikator atau satu arah menjadi bentuk komunikasi dimana komunikan saling berinteraksi, karena itulah keberadaan media sosial sangat penting.

Media sosial adalah sebagai media untuk berhubungan antar manusia dan hubungan itu bertujuan untuk mencapai sebuah kualitas kehidupan yang lebih baik atau dalam pemikiran Turkle (2011:13), "technology proposes itself as the architect of our intimacies". Pernyatan dari Turkle ini mengindikasikan bahwa seharusnya pembicaraan atau interaksi dalam mencapai intimasi adalah sebuah keniscayaan. 
Fokus penelitian ini berupa pembicaraan di media sosial Facebook dimana data diambil dari percakapan yang dikirim oleh pengguna dimana ada di dalam sistem penulis dan ditanggapi secara massif oleh pengguna lainnya walaupun penulis tidak mengenalnya. Beberapa contoh 'screen shoots' yang bisa diambil oleh penulis seperti dibawah ini :

Dari 18 capture perbincangan yang diambil dari sebuah pernyataan yang disampaikan oleh Ade Armando di media sosial Facebook pada tanggal 25 Maret 2016, pukul 3:51 pm mengenai, "Paus Fransiskus membersihkan dan mencuci kaki pengungsi Muslim di Italia. "kita adalah saudara yang ingin hidup dalam perdamaian,"kata Paus" (disertai dengan foto ketika Paus melakukan penciuman kaki)"

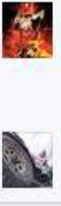

Akmal Sulaiman Zulkurnain dosen JIL karena sayang duit buat naik haji bilang hukum waijb haji tidak relevan......bilang tidak boleh piligami tetapi lihat daun muda eh jadi boleh....pilih pemimpin karena rupiah eh jadi milih yg non muslim Like · Reply 3 hrs

Write a comment...

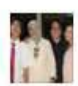

Ade Armando

March 25 at $3: 51 \mathrm{pm} \cdot$ e

Paus Fransiskus membersihkan dan mencuci kaki pengungsi Muslim di ltalia "Kita adalah saudara yang ingin hidup dalam perdamaian," kata Paus.

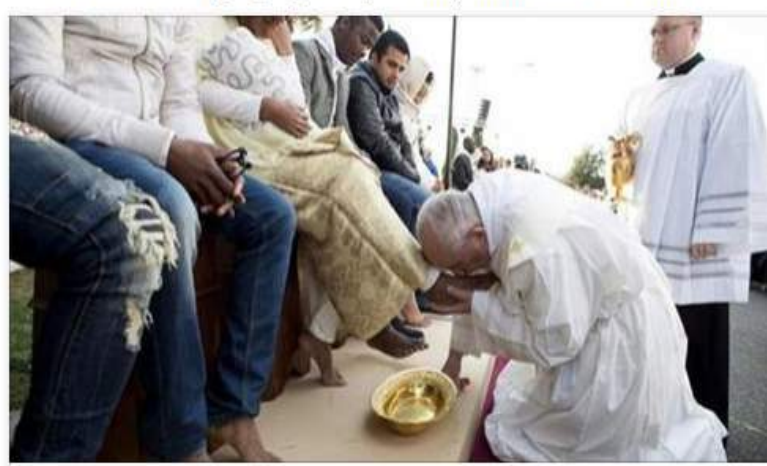

Paskah, Paus Fransiskus Cium Kaki Muslim dan Kecam Bom Belgia

Paus Fransiskus meminta 12 orang yang kakinya dibasuh dan dicium untuk berdoa sesuai agama masing-masing demi perdamaian dunia.

NEWS.LIPUTANG. COM I BY LIPUTANE.COM
Pernyataan tersebut kemudian ditanggapi secara massif oleh pengguna lain yang terkait dengan teman yang ada dalam sistem pemberi pernyataan. Ketika seseorang mencoba menggunakan teori CMM dalam memaknai pernyataan tersebut, maka sampai pada tahapan episodes, yakni seperti dikatakan oleh West \& Turner (2014:95), “ episodes describes contexts I which people act". Karena itu apabila kita bicara konteks maka kita berusaha untuk memaknai latar yang coba memberikan gambaran tentang Pembasuhan Kaki, maka bisa mengaitkannya dengan suatu peristiwa Perjamuan Terakhir. Simbol dari Pembasuhan Kaki menurut tradisi Yahudi adalah penghormatan seseorang terhadap orang yang mempunyai status atau jabatan, namun makna pembasuhan kaki

Like - Reply - B3 - March 25 at 3:55pm

9. Manuel Pribadi harusnya ini menjadi contoh tuk ajaran agama tetangga Like - Reply : B 3 - March 25 at 3:56pm

32. Fitria Finata Sugiharto Ini sy sbg nasrani ga lihat Dari segi agama tp Dari segi kemanusian krn kita memang hrs slg menolong Dan melayani sesama umat manusia, "damai bwt Indonesia" Like - Reply - B $10 \cdot$ March 25 at 4:04pm - Edited M Z Arifin Umar Win2 solution semua.

Like - Reply - March 25 at 4:07pm

8. Edi Herlanto Van Jaitan Utk menjalin kedamaian tentunya kan saudaraku ???

Like - Reply - B1 - March 25 at 5:54pm

Write a reply..

Intan Diamond Dust Ini fasti ada unsur kristenisasi... siafin fentung!!! Like - Reply - B 3. March 25 at 4:10pm

2. Abu Djibril Bagaimana mungkin tangan dan hidung popes yang najis mencium

(1) kaki yang 5 kali di sucikan ... ini ritual tahunan yang aneh

Like - Reply - March 25 at 4:11pm - Edited

A Hide 43 Replies

gX Fitria Finata Sugiharto Tetep ya....msh ada aja yg nyinyir...lya deh org suci...terserah lo aja. Like - Reply $\cdot$ B $2 \cdot$ March 25 at 4:12pm

20. Abu Djlbril Fitria Finata Sugiharto bukan begitu.. muslim yang baik tidak mungkin mau di sentuh oleh orang kafir jika punya wudhu.. apalagi di cium Like - Reply - March 25 at 4:13pm

2. Abu Djibril ini berita yang benar, bahwa ini ritual tahunan dan dilakukan seleksi yang akan di cuci kakinya oleh popes http://www.aljazeera.com/../pope-francis-washes-refugees... 
yang dilakukan Yesus adalah salah satu bentuk pengajaran bagi murid-muridnya bahwa penghormatan adalah bukan bentuk dominasi tetapi bentuk keteladanan, kesetaraan, dan bentuk pelayanan.

Selain seseorang mengetahui konteks dari sebuah percakapan, maka seseorang juga harus mengetahui hubungan antar individu yang terlibat dalam percakapan dan tindakan yang dilakukan dalam percakapan (speech act). Ketiga elemen tersebut dapat memperlihatkan bagaimana suatu percakapan tersebut bisa membentuk sebuah hubungan yang lebih baik. Kalau seseorang melihat dari salah satu percakapan mengenai Tindakan Paus sebagai pemimpin umat Katolik dengan mencium kaki seorang muslim,

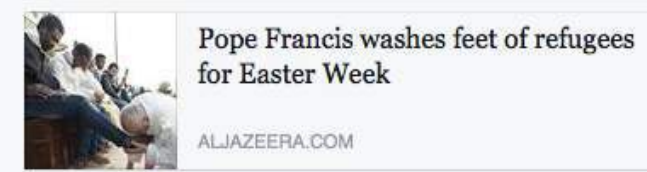

Like - Reply - B1 - March 25 at 4:14pm

Intan Diamond Dust Hahaha ini orang yg kerasukan ajaran arab ada yg mencak2

Like - Reply - B2 - March 25 at 4:14pm

12. Abu Djibril ioh.. bukannya ajaran kristen itu ajaran eropa? dan ajaran hindu dari india ? (:)

Like · Reply - March 25 at 4:15pm

Intan Diamond Dust lya sama aja. Budaya arab kan yg suka koar2 aurat wkwkwkwk.

Like - Reply - B1 - March 25 at 4:16pm

W. Abu Djibril Intan Diamond Dust, loh.. dalam islam itu ada batasan aurat loh... dimana perempuan itu seluruh tubuhnya adalah aurat yang tidak boleh di lihat laki laki bukan muhrim , kecuali wajah dan telapak tangan Like - Reply · March 25 at 4:17pm

Intan Diamond Dust Yg suka koar2 haram ama budaya lokal... budaya arab is the best lah... pake cadar, ngomong akhi dan ukhti dsb... Like - Reply - B2 - March 25 at 4:17pm

Abu Djibril Intan Diamond Dust loh. budaya lokal itu seperti apa, kristen budaya lokal ? atau hindu ? atau konghucu ? Like · Reply · March 25 at 4:19pm

Intan Diamond Dust Ketahuan budaya arab itu ngajarin laki jadi gampang ngaceng wkwkwkwkwk... tkw tuh pada diperkosa tuannya. Like - Reply - B2 - March 25 at 4:19pm

Q. Intan Diamond Dust Oooh sebelum ada hindu tuh di sini udah punya budaya sendiri. Tau mesopotamia kan? Sebelum ajaran arab masuk mereka punya jati diri.

Like - Reply - B2 - March 25 at 4:20pm maka dapat ditemukan beberapa kategori penting, yakni ; (1)Toleransi Agama (sikap saling menghargai), (2) Penyamaan keyakinan dengan identitas bangsa/suku, (3) Ketidakpercayaan terhadap berita yang ditampilkan, (4) Fundamental agama (egoisentrisme agama).

\section{Hasil Penelitian dan Pembahasan}

Penelitian ini mencoba menelusuri kategori yang bisa didapatkan dari satu topik pembicaraan yakni tentang keyakinan sebuah agama. Pada penelusuran bisa didapatkan bahwa perbincangan tentang topik keagamaan pada akhirnya dikaitkan dengan penyerangan terhadap keyakinan individu lainnya dan menekankan bahwa terjadi egoisentrisme agama.

Abu Djibril Intan Diamond Dust loh kalo ngaceng semua laki laki akan ngaceng kalo melihat perempuan, apalagi sexy tapi dalam islam ada aturan dan batasan loh

Like - Reply - March 25 at $4: 20 \mathrm{pm}$

是 Intan Diamond Dust Aaaah palingan saya dibilang muslimah abal2, kafir dsb.. dah sering.

Like - Reply - B1 - March 25 at 4:20pm

Intan Diamond Dust Hahahaha di bali mana ada pemerkosaan? Padahal banyak bule sliweran pake bikini. Coba klo arab. Like - Reply - B2 March 25 at 4:21 pm

7. Abu Djibril Intan Diamond Dust wah.. teh intan bukan muslimah abal abal , kalo memang muslimah karena teteh belum mempelajari islam dengan baik itu saja

Like - Reply - March 25 at 4:21 pm

Abu Djibril di bali ada pemerkosaan siapa bilang tidak ada... beberapa kali kasus terjadi bahkan ada loh kasus perkosaan berantai di bali... ga tau ya .... (:)

Like - Reply - March 25 at 4:22pm

E. Intan Diamond Dust Oooh mana bisa... saya jebolan ponpes jeh. Like - Reply - B2 - March 25 at 4:22pm

Abu Djibril wah.. kalo teteh jebolan ponpes pasti adalah muslimah yang baik... cuma mungkin ustad2 nya kurang memberi pemahaman Like - Reply - March 25 at 4:24pm

25. Ari Sudarsono Gacor gak mutu si Abu nih Like- Reply B2 - March 25 at 4:31pm

Abu Djibril Ari Sudarsono koq ga mutu, ini fyi aja, bahwa seorang muslim itu kakinya disucikan $5 \mathrm{x}$ dalam sehari dan ga mungkin mau di basuh oleh tangan popes yang najis apalagi di cium oleh hidungnya atau di jilat oleh lidahnya .. ga mungkin Like - Reply - March 25 at 4:32pm Purbo Ariyo Setiyo Baru tau saya kalo kristen itu dari eropa ...8 Like - Reply - B2 $\cdot$ March 25 at 4:32pm

Gambar 3. 
Edison Slahaan Padahal, mereka jadi pengungsi akibat ulah saudara se-ukhuwah mereka juga \& kabarnya, banyak para pengungsi yg akhirnya sadar, betapa buruknya ajaran agama yg mereka anut selama ini.

Like - Reply - B 1- March 25 at 4:33pm

T. Abu Djibril Purbo Ariyo Setiyo, ajaran kristen itu di bawa oleh penjajah dari eropa yaitu inggris, prancis, spanyol dalam rangak Gold GOspel dan Glory, gold adalah mencari kekayaan, gospel adalah menyebarkan agama dan gloryt adalah mencari kejayaan.. belajar sejarah bro Like - Reply - B 1 - March 25 at 4:34pm

D. Intan Diamond Dust Padahal sama aja... sama2 dari penjajah. Baca sejarah babad bali majapahit. Like - Reply - B 1- March 25 at 4:36pm

Abu Djibril Edison Siahaan, mereka umumnya penganut syiah , sebagian katolik dan juga suku kurdi yang beragama paganis Like - Reply · March 25 at 4:36pm

Fi. Abu Djibril Intan Diamond Dust, Islam datang melalu organisasi wali songo dan para pedagang, umumnya para pangeran yang sebelumnya beragama hindu yang berasal dari india tertarik dengan islam oleh sebab itu mereka menjadikan kerajaan menjadi kesultanan .. baca sejarah dong (:)

Like - Reply - March 25 at 4:38pm

12. Abu Djibril koq saya malah ngajarin dosen sekelas ade armando ya.. maaf kang Ade Armando, bukan saya ngajarin atau ngeguruin tapi wujud kasih sayang ane sebagai sesama muslim jangan sampe ente ketularan LGBT atau jadi banci, yang kedua jangan sampe ente jadi murtad (:)

Like - Reply · March 25 at 4:42pm

Abu Djibril Intan Diamond Dust orang bali itu setia dengan budaya hindustan, acha acha acha... :)

Like - Reply - March 25 at 4:45pm

Intan Diamond Dust Baca sejarah babad tanah bali dan suku tengger jangan dinina bobokkan ama sejarah palsu...

Like - Reply - B 1- March 25 at 4:45pm
5.2. Abu Djibril Intan Diamond Dust loh... sejarahnya sama dengan suku

baduy, mereka melarikan diri karena terdesak oleh kesultanan kesultanan yang nota bene saudara saudara mereka sendiri yang sudah memeluk islam, bukan orang arab loh (:)

Like - Reply - B1 - March 25 at 4:46pm

20. Abu Djibril Intan Diamond Dust dulu di arab juga sama menyembah patung koq jadi menyembah patung itu budaya arab juga dulunya Like - Reply · March 25 at 4:53pm

2. Mark Rifandi Udahah, enthe jualan farfum sana...jgn lupa bawa fentung buat jaga2 klw ada maksiat, langsung deh fentung fentung Like - Reply @1 1 March 25 at 4:55pm

Abu Djibril Mark Rifandi kalo ente suka maksiat pantes aja hhhhhhh Like - Reply - March 25 at 4:59pm

7.- Soni Blanterang de Rosari Sudah 1400 usia agama Islam, tapi kamu masih berkutat pada halal haram. Kafirin orang segala. Makanya gak ada otaknya. Ngak bisa lakukan inovasi, hanya konsumtif produk kafir aja. Lu main FB yg bikin kafir, handphone, listrik, mobil, loud speaker di masjid. semua kafir yg nemuin. Kasihan lu. Apa ug sdh lu ngimbangi untuk kesejahteraan manusia.

Like - Reply - B 3. March 25 at 5:36pm

Keajaiban Hati Abu Djibril berdiskusi dgn tenang tanpa emosi dan berdasarkan pada ilmu pengetahuan. Sya suka gayanya. (c) Like - Reply B B - March 25 at 5:39pm

82 Kim Nan Ce malu2in yg seagama nih orang kayak abu gosok Like - Reply - B2 ' March 25 at 5:39pm

20. Hermes Santika Abu Djibril sy mau ksh anologi begini : kesampingkan apa yg dlakukan si Pope ini sbg ritual keagamaan. Sharusnya sbg PEMIMPIN AGAMA hrs bs meLAYANI, meRENDAHkan DIRI, dan menjadi contoh baik thadap nilai2 kemanusian. Pemimpin agama itu bkn mau diLAYANI... See More

Like - Reply - B 3. March 25 at 6:09pm
Dzlky Truck Corp Perdamaian dlm sosial \& kemanusiaan seperti halnya kehidupan rill di luar sosmed (/di lapangan)

Like - Reply · March 25 at 4:11pm

Doting Suryadi Suryadi HOAX!

Like - Reply · March 25 at 4:17pm

FX Fitria Finata Sugiharto Berita aslinya Dari TIMES Dan itu bkn abal2 ky kbanyakan media di Indonesia bro....

Like - Reply - B1 - March 25 at 4:21pm

Doting Suryadi Suryadi Pake akal sehat kala lihat dan baca berita. Like - Reply - March 25 at 4:22pm

23. Abu Djlbril intinya ga mungkin kalo muslim mau di cium oleh hidun paus yang najis, karena kaki seorang muslim di sucikan sehari $5 \mathrm{x}$ Like - Reply - March 25 at 4:26pm

1. Doting Suryadi Suryadi Nggak semua pengungsi Suriah itu muslim. banyak juga yang kristen ortodok. Mereka orangorang Kristen Ortodok Syria, tao...!

Like · Reply - March 25 at 4:33pm

D. Intan Dlamond Dust Kristen orthodox ada ritual wudhu sebelum sholat. Like - Reply - B 1 - March 25 at 4:36 pm

4. Doting Suryadi Suryadi Pengungsi Suriah mosok orangnya 'hideung' ? WEEEEEEEK $\ldots . .$. !

Like - Reply - March 25 at $5: 17 \mathrm{pm}$.

C. Toni J Nonton tv brooo... biar nggak kliatan begonya elo.. Like - Reply - March 25 at 5:27pm

7.-2 Soni Blanterang de Rosarl Ngatain orang kafir, di Facebook yg diciptain orang kafir, kasihan banget lu orang Like - Reply · March 25 at 5:38pm

Doting Suryadi Suryadi Emang kalo nonton tv lantas loh jadi pinter ? Banyak berita hoax di tv, bego ! Like - Reply - March 25 at 5:41pm

Gambar 7
Gambar 6

Albet Triyanto Kalau dia benar2 muslim yang taat, pasti tidak mau dicium kakinya. hah modus.

Like - Reply - March 25 at 4:21pm

10 Edison Siahaan Ya ealaaahh.. kan lu bukan pengungsi?? Lu, anjing gila, ga merasakan penderitaan para pengungsi akibat ulah sdr se-ukhuwah mereka sendiri.

Like - Reply - March 25 at 4:35pm

(1. Bisyir Abdullah Uupps ada batok botak ngamuk.. Like - Reply · March 25 at 5:53pm

7. Albet Trlyanto Mungkin dia lagi lapar om.. Like · Reply · March 25 at 5:55pm

D. Write a reply...

Then DJII Liung Sebaik apapun prilaku seseorang pasti ada yg selalu berpandangan negatif dan kotor. Seperti nenek nya Tapasha.

Like - Reply - B1 - March 25 at 4:29pm

10. Edison Slahaan Mereka berpandangan negatif tuh, semata mata meneladani junjungan mereka.

Like - Reply $\cdot$ B 2 March 25 at 4:36pm

Then Djli Liung Hati nurani mereka sudah buta dan mati rasa Like - Reply · B1 March 25 at 4:37pm

D. Write a reply...

Hlsyam Aby Ada udang di balik bakwan

Hati"saja lah jgn terperangkap

Like - Reply - March 25 at 4:37pm

10 Edison Siahaan subhanallah.. sikap su'uzon kaya lu ini adalah ajaran dari nabi arab..

Like - Reply · March 25 at 6:18pm

Gambar 8. 
matu Geong Dinatara mualans terına kasin alas perjeldasannya, selamat jg km telah menemukan pencerahan di agama barumu, sy juga terlahir di kluarga yg islam, tapi sy lebih menggali local wisdom skrg terutama kejawen dan pas banget dengan pandangan sy bahwa semua agama itu ... See More

Like - Reply - B1 - March 25 at 6:41pm

Te Rinny Srihartini ( Mhn maaf seblmnya pd umat Nasrani). Begitulah umat agama lain bisa menerjemahkan apa yg dilakukan Paus itu. Skg jaman sdh berbeda. Keteladan Yesus soal merendahkan diri yg trs dijadikan tradisi itu mungkin tdk cocok Ig dilanjutkan pd masa skg dimana ... See More

Like $\cdot$ Reply $\cdot 19$ hrs

Write a reply..

Papah Varel maksudnya cium kaki apa? geli tau...

Like - Reply - March 25 at 4:53pm

19 Edison Siahaan Itu tradisi para paus dari jaman dahulu kala, nyet.. masih lebih baik daripad membunuhi para pengungsi seperti yg dilakuken ISIS teroris islam..

Like - Reply · March 25 at 6:19pm

Dapah Varel oh gitu ya nyet. membunuh dn mencium kaki ya gk bisa dibandingkan nyet. gmn sih onyet satu nih

Like - Reply · March 25 at 7:23pm

4 View more replies

Write a reply.

Iskandar Malik Para ulama wajib mencium kaki saya wkwkwk....

Like · Reply · March 25 at 4:55pm

Iskandar Malik Ayo...onta onta...neh kaki saya...ayo cium! Hahaha...geblek tenan.

Like - Reply · B1 - March 25 at 4:56pm

Zhu Doenx paus nya bijak cecunguk nya yg kayak gini nich yg bikin rusuh

Gambar 9.

Shantoy Hades Saya membayangkan Habib Rizik begitu di kaki Ahok.

Like - Reply - B1 - March 25 at 4:56 pm

Zhu Doenx mencuci kaki kan ajaran kristiani gak ada dalam islam...plis dech

Like - Reply - March 25 at 5:46pm

(9)

Shantoy Hades Kurang baca yah? Hehehe

Like - Reply - March 25 at 6:09pm

D. Write a reply...

T17 Ade Armando Kaget saya membaca komentar negatif tentang apa yang dilakukan Paus. Dia sudah begitu merendahkan diri dan masih juga dicaci? Like - Reply. B $7 \cdot$ March 25 at 5:02pm

^ Hide 29 Replies

Abu Djibril ini bukan komentar negatif de, tapi peraturan dalam islam itu tidak boleh di cium kakinya oleh hidung paus yang najis karena kaki kita orang islam sudah di sucikan $5 \mathrm{x}$ sehari loh Like - Reply - March 25 at 5:07pm

F. Andri Riswandi @Abu Dzibril.. Maaf bapak.. Saya orang awam.. Peraturan islam mana yg mengatakan seperti itu.?

Like - Reply - B 1 - March 25 at 5:10pm

T7. Ade Armando Aturan yang tercantum di mana ya? Like - Reply - B1 - March 25 at 5:12pm

F. Abu Djibril yang ente posting adalah ritual paskah yang dilakuan setahun sekali , dimana di pilih 12 orang yang akan di basuh kakinya oleh popes, sekarang peraturannya boleh non katolik dan juga boleh wanita yang sebleumnya hanya untuk katolik dan laki laki... baca de.... ente posting sesuatu itu ada maksud, ente akan rasain kalo mereka menjadi mayoritas di negeri ini... inget kasus perang ambon de Like - Reply - March 25 at 5:12pm

17 Ade Armando Saya tanya ya, di mana ada aturan yang menyatakan kaki seorang muslim tidak boleh dicium non-muslim?

Like - Reply - B 1 - March 25 at 5:13pm

Gambar 11
Mudians Ruud Comments negative sesuai dgn pikiran, pikiran negative sesuai ajarannya. Like - Reply - B2 March 25 at 4:43pm

Ratu Geong Binatara buat kaum nasrani sy mau tanya, apa artinya mencium kaki orang kyk gitu?? Tolong jawab krn kalo ga ada makna apa2 menurut gw ya berlebihan saja seorang paus yg terhormat mau melakukan itu. $\mathrm{Yg}$ bagi pandangan umum merendahkan diri :-:

Like - Reply - March 25 at 4:45pm

Abu Djibril saya juga mau di cium kakinya, tapi sambil pake sendal terus pentungin ke jidatnya paus hhhhhhhh

Like - Reply · March 25 at 4:50pm

A. Rudlans Ruud Mbak ratu, dulu sewaktu sy msh muslim punya pemikiran yg sama dgn mbak. tp sekarang sy jd tau itu maksudnya bahwa manusia itu harus merendahkan dirinya dan melayani terhadap sesama manusia. tidak penting setinggi apapun pangkat dan derajatnya karena TUHAN telah melakukan hal itu. menjadi sama seperti manusia lalu merendahkan dirinya dan melayani bahkan dianiaya dan disalibkan. Like - Reply · March 25 at 5:10pm

Audlans Ruud Abu jibril. jujur saya katakan, sy marah anda melecehkan sprt itu, andai sy masih org islam mungkin saya akan memaki anda dan mengajak berkelahi, tapi sebagai orang yg sudah menjadi pengikut Kristus saya harus memaafkan anda. Like - Reply - March 25 at 5:16pm

8.- Soni Blanterang de Rosari Abu jibril kasihan banget, berkata kotor d Facebook yg notabene produk temuan orang kafir. Kira2 halal apa haram ya

Like - Reply · March 25 at 5:40pm

5X Fitria Finata Sugiharto Paus itu meniru teladan Yesus...karena Yesus mlakukan seperti itu kpd murid2Nya. Artinya kita harus menjadi penolong bagi smua manusia Dan menghormati siapa pun mreka karena walau kita beda keyakinan/budaya/status sosial kita ini sama" manusia. Like - Reply - B 1 - March 25 at 5:51pm

I8: Heri Nurdiawan Syah Kami berharap PAUS bisa mencuci juga kaki Jendral-Jendral negeri barat yang memerintahkan pemboman anakanak, perempuan di negeri muslim serta negeri Indonesia saat dijajah

Gambar 10.

97. Andri Riswandi Ade Armando karena mereka merasa lebih mulia pak.. Harap dimaklumi.. (:)

Like - Reply - B2 - March 25 at 5:13pm

T2. Ade Armando Andri Riswandi lya, begitulah... Like - Reply - B 1 - March 25 at 5:14pm

72. Abu Djlbril Ade Armando Hai orang-orang yang beriman,

Sesungguhnya orang-orang yang musyrik itu najis (QS At-Taubah : 28) Like - Reply - March 25 at 5:14pm

77. Ade Armando Jangan ngarang ah. Itu kan bicara tentang kaum musyrik yang dilarang mendekati Masjidil Haram.

Like - Reply $\cdot$ B2 $\cdot$ March 25 at $5: 17 \mathrm{pm}$

Abu Djibril Ade Armando koq ngarang, alquran itu jelas loh Like - Reply - Maroh 25 at 5:20pm

Abu Djibril Ade Armando itu ayat berikutnya dimana mereka tidak boleh mendekati masjidil haram, lha mendekati masjidl haram aja tidak boleh apalagi disentuh mereka... tapi solusinya adalah wudhu kalo memang kamu punya wudhu

Like - Reply - March 25 at 5:22pm

F. Andri Riswandi Bapak abu Djibril.. Tolonh d lanjutkan arti potongan ayatnya..

Terus apa pengertian musyrik itu.? Bukankah seseorang yang menyekutukan Tuhan? Dan itu berlaku untuk umat Islam.. Lantas kenapa bapak menisbatkannya kepada Paus.? Like - Reply - B1 - March 25 at 5:25pm

Fy Andri Riswandi Apakah kita lebih mulia daripada masjidil haram.? Like - Reply - B 1 - March 25 at 5:28pm

T4. Ade Armando Abu Djibril: Anda itu memotong ayat seenaknya saja. At Taubah itu bercerita tentang pengkhianatan kaum Musyrik setelah melakukan kesepakatan dengan Nabi. Kaum Musyrik itulah yang dikecam dalam surat tersebut. Anda tidak boleh membohongi lawan bcara Anda. Sebagai muslim, sikap Anda memalukan Like - Renlv - M 4 - March 25 at 5:29nm

Gambar 12 
1. Pleces Bramana Islam NU dan Mugamadiyan yg mayoritas dı negerı inı kayaknya tdk sprt itu

Like - Reply - B1 - March 25 at 6:19pm

David Firman Yg kakinya dicium aja ngga apa2. Nah ini yg siapa jg yg kepo abu gosok malah kebakaran jembut Like - Reply · March 25 at 6:39pm

Ratu Geong Binatara in pak ade, abaikan saja org yg garis keras begitu, biasanya org spt itu wahabrott salafi pembawa sial:D Like - Reply - B1 - March 25 at 6:47pm

Galang Mesya Fansy Jangankan Paus bang Ade, Yesus dulu dibencinya lebih parah, sampai di salib. (:) Like - Reply · B2 March 25 at 7:30pm

Rudlans Ruud Abu sudah sama dgn orang2 munafik penjual ayat2. dia ambil sepotong ayat cuma utk kepentingan dan keuntungan sendiri. anda gak malu mencemarkan iman anda dan anda gak malu masih gunakan produk org kafir.

Like - Reply - March 25 at 8:53pm

D. Write a reply...

Shantoy Hades Jangan kaget bang, pendapat negatif hanya refleksi dar sempitnya ruang pikir

Like - Reply - B1 - March 25 at 5:03pm

r.

Ade Armando lya. Tapi sedemikian sempitnya ...

Like - Reply $\cdot$ B2 $\cdot$ March 25 at 5:12pm

Papah Varel saya juga kaget waaaw sungguh tak kuduga

Like - Reply - B1 - March 25 at 5:24pm

Papah Varel Sungguh Islam telah mengajarkan semuanya. bagaimana cara kita bersikap thdp sesama muslim maupun non muslim. Islam agama yg indah. Islam tdk menyuruh ummatnya merendahkan diri, tapi berperilakulah yg mulia.

Like - Reply - B2 March 25 at 5:26pm

Edison Siahaan Taqiyya, ni yeee.. cuih lu!l mendingan lu bantu para pengungsi itu daripada cuma ber-taqiyya macam monyet agi mimpi jorok.

Gambar 13

Erens Dimu Heo Pelaku SARA tok punya landasan dlm beragumen? Ayat2 suci sering ditampilkan sebagai dasanya.

Like - Reply - 9 hrs - Edited

2 Write a reply...

Jaqublak Damanik

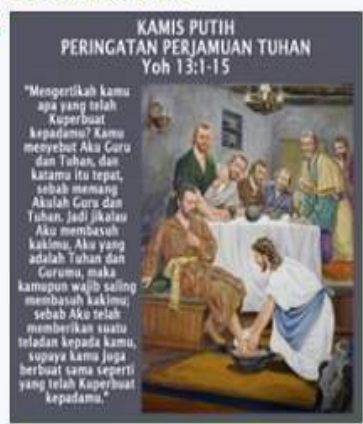

Like - Reply - B2 - March 25 at 6:12pm

$11=$

Inaska Fani Hanja hrs dihormati paus.... tp foto tdk pernah cukup tuk mencerita sesuangguhnya

Like - Reply - B 1 - March 25 at 6:12pm

David Firman Setujuuu

Like - Reply · March 25 at 6:40pm

6. Inaska Fani Hanja David Firman heee

Like - Reply - March 25 at 7:38pm

Write a reply...
LFW Fitri Adona Ketika Nabi Muhammad SAW dicium tangannya, beliau jadi merasa kurang enak dan buru2 balik mencium tangan yang bersangkutan. Peacel Like - Reply · March 25 at 5:41 pm

10 Edison Slahaan Eh yg bersangkutan habis garuk kantong menyan, pula. Peace!l

Like · Reply - March 25 at 6:15pm

D. Write a reply.

Erens Dimu Heo membaca beberapa komen diatas, sebenarnya kita bisa disadarkan bahw tak jarang para pemeluk agama lebih buruk kelakuannya daripada yang tak beragama. Apakah memang agama mengarahkan pengikutnya demikian?

Like - Reply · March 25 at 6:29pm · Edited

TV Ade Armando Kalau memahami agama dengan sempit, ya beginilah jadinya ....

Like - Reply - B 1 - March 25 at 6:09pm

A Edison Siahaan Begitulah typical budak arab.

Like - Reply . B 1 - March 25 at 6:16pm

Papah Varel org yg buruk klakuannya hanyalah org2 yg mngaku2 beragama. sedangkan sebenar2nya org yg beragama apalagi yg beragama Islam, dia akan memiliki sikap yg mulia, berwibawa dan bersahaja spt baginda Nabi Muhammad Sollollohualaihiwasallam. indahnya Islam

Like - Reply - March 25 at 7:30pm

Erens Dimu Heo Agama punya kecenderungan membentuk

watak/karakter pengikutnya... Sy berpikir, daripada mengklaim, lebih baik melakukan gerakan perubahan... mengikis bagian2 buruk -yg bisa saja merupakan kekilafan masa lalu (sejarah)? mungkin itu akan menyempurnakan suatu agama?

Like · Reply $\cdot 11$ hrs · Edited Like $\cdot$ Reply $\cdot 15$ hrs

2.

Yuni Mahrifah Tepung terigu ya mazz.??

Ve. Donlu, 12 hre

Gambar 14

Tsutchie Choe Bagi semua yg "berkonflik" dlm postingan ini :

Dlm postingan ini disebutkan bhw: Paus mengikuti keteladanan Yesus mencuci dan mencium kaki 12 pengikutnya pada perjamuan terakhir sblm wafat. (garis bawahi 12 pengikut : artinya yg $12=$ kristiani).

Bagi yg Kristiani (Paus) mgkn sebaiknya tdk melibatkan yg Muslim dlm ritual keagamaan Kristen. Byk cara lain yg bisa dilakukan sbg bentuk kerukunan/perdamaian dim "ke-heterogen-an"

Bagi yg Muslim : dlm ajaran ISLAM diajarkan menghormati/menyayangi sesama, bahkan semua makhluk termasuk hewan/tumbuhan. Contoh, menyembelih hewan ada adabnya (do'anya). Rasulullah pun pada masanya hidup berdampingan dgn yg bukan Muslim. Di suatu kisah dlm sejarah Nabi Muhammad menyuapi seorang Yahudi buta yg selalu mencaci-maki Nabi. Dia tidak tahu kalau yg menyuapinya seorang yg bernama Muhammad yg dia caci. Makanya dikatakan ISLAM itu rahmat untuk sekalian alam.

Bagi yg MUSLIM : bagimu Agamamu - bagiku Agamaku. "' tidak mengikuti ritual agama di luar ISLAM agar tidak men-"distorsi' Agidah yg diyakini. SALAM !!!

Like $\cdot$ Reply - B 3. March 25 at 6:50pm

D- Papah Varel luar biasa komentnya. sungguh Indahnya ISLAM. Islam membawa kedamaian bahkan ketika menjadi mayoritas ttp mendamaikan, lihatlah di Indonesia semua agama ttp aman Like - Reply - B1 - March 25 at 7:34pm

Abu Djibril Papah Varel itulah yang disebut rahamatan lilalamiin Like - Reply - March 25 at 8:38pm

2. Mashur

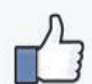

Like - Reply · March 25 at 9:18pm

A. Write a reply...

Kholld Bwz Bau titit lo Armando.......mampus aja lo eneuk gw liat lo Like - Reply · March 25 at 7:47pn

Faj Ar T Wib Ayoo ndang ditiru...patut sebagai suri tauladan bagi kaumnya ..

Gambar 15.

Gambar 16. 
Aprilia Fani Bener ini perdamaian ?? Aku lebih percaya Kalamullah dim al quran.. Org2 kafir dan nasrani itu ngga akan pernah ridho thd orang2 muslim. Sampai mereka mengikuti ajaran nya....

Bisi we ieu mah modus hungkul.. Perdamaian2 apek teh ujung2 na tauhid dipertaruhkan kudu milu ka agama maranehna.. Naudzubillaah..... See More Like - Reply · B1 - March 25 at 8:47pm

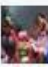
Abu Fadhel Pencitraan itu (:) ... mau nggak paus cium kaki saya Like - Reply - B1 - March 25 at 9:06pm - Edited

a Ceppy Soneta Giliran orang Kristen dibangga2in, eh giliran orang Islam postingnya korupsi sama kekerasan nya melulu, mungkin si ade armando lapar. Like - Reply B1 - March 25 at 10:06 pm

Nico Wijaya Selamat merayakan jumat agung bagi temen" ku yang Katolik n Kristen.

Like - Reply - B2 $\cdot$ March 25 at 10:45pm

Love

Tresno Bambang substansinya adalah kerendahan hati dimana ada kerendahan hati disitu ada perdamaian.

Like - Reply - B 3 - March 25 at 11:52pm

we Ari Widodo Preet

Like - Reply - Yesterday at 1:22am

Fes Heri Nurdlawan Syah Kami berharap PAUS bisa mencuci juga kaki Jendral-

Jif- Jendral negeri barat yang memerintahkan pemboman anak-anak dan perempuan di negeri muslim sekarang serta negeri Indonesia saat dijajah dulu.... orang-orang tua kami tewas atas perbuatan jendral kolonial Belanda/Sekutu yang haus nyawa, harta dan agama (Gold Gospel Glory) Like - Reply - 20 hrs

Romanus Sumaryo Indonesia sbg negara mayoritas muslim bisa menjadi negara maju kalau mayoritas muslimnya berpikiran maju. Kalau tidak, jangan harap Indonesia bakal jadi negara maju. Apa ada negara2 Islam yg menjadi negara maju? Saya rasa bukan krn Islamnya tp krn mayo... See More Like - Reply - B3.17 hrs

Gambar 17.

(1) Kategori Toleransi Beragama (sikap saling menghargai)

Toleransi seperti dikatakan oleh Mahatma Gandhi, "... each is right from His own point of view, but it is not impossible that everyone is wrong; hence the need for tolerance. By cultivating in ourselves tolerance of other views, we acquire a truer understanding of our own"

Pernyataan Gandhi ini memberikan gambaran bahwa toleransi menempatkan atau menanamkan cara berpikir atau cara pandang orang lain di dalam cara pandang kita. Dalam percakapan yang terjadi hanya pada beberapa pesan, seperti misalnya pernyataanpernyataan yang muncul dalam percakapan,

"Indonesia sebagai Negara mayoritas muslim bisa menjadi Negara maju kalau mayoritas muslimnya berpikiran maju"
Arif Winata bukan pengikut islamnya yg tidak bertikiran maju,tapi karena masih banyak muslim yang tahu betul buat apa dia hidup didunia,biarlah kenikmatan didunia ini banyak untuk selain nonmuslim,karena muslim mengharap balasan yang lebih baik dari kekayaan,ataupun kekuasaan didunia

Like - Reply - 9 hrs - Edited

T.7.

Romanus Sumaryo Eeemmm... maksudnya gimana mas? Coba bisa diulangi...(c)

Like $\cdot$ Reply $\cdot 9$ hrs

Write a reply...

Romanus Sumaryo Saya ingat pernah membaca percakapan, Nabi Muhammad kepada salah seorang sahabatnya, kira2 begini isinya bhw Nabi melihat bhw di masa mendatang Islam akan tertutup oleh kaum muslim. Sila artikan sendiri maksudnya, to kalo saya menangkap itu sebuah keluhan atau kekhawatiran dat seorang besar yg menurunkan Islam Like - Reply B $1 \cdot 17$ hrs

Arif Winata seorang muslim diakhir zaman akan banyak namun baga buih dilautan terombang ambing,karena apa? karena cinta dunia dan takut mati,jadi muslim akan kuat bila tidak mengejar dunia,kalau nonmuslim mungkin kejayaan didunia yang dikejar,semoga banyak muslim yang semakin sadar tujuan hidupnya, dan tidak menyia-nyiakan waktu untuk mengejar dunia, inilah esensi muslim dan nonmuslim Like $\cdot$ Reply $\cdot 9$ hrs

7. Romanus Sumaryo Betul bung Arif Winata contohnya adalah tg mengejar kekuasaan dunia, entah itu jd capres, cagub, cabup, cawalkot yg bawa2 sentimen agama padahal kemampuan pas2an Like - Reply $\cdot 8 \mathrm{hrs}$

W. Write a reply..

S Teguh Windoto harga sebuah kasih, dan perdamaian dunia .. Like - Reply - 14 hrs

Don Aditya Giliran orang Kristen dibangga2in, eh giliran orang Islam postingnya korupsi sama kekerasan nya melulu, mungkin si ade armando belum sunat.

Gambar 18.

" sungguh Islam telah mengajarkan semuanya. Bagaimana cara kita bersikap terhadap sesama muslim maupun non muslim"

"tak jarang para pemeluk agama lebih buruk kelakuannya daripada yang tak beragama"

Pernyataan di atas mengindikasikan bahwa ada keinginan untuk tidak mempermasalahkan cara pandang yang dimiliki pengguna lain, mereka juga cenderung untuk mendorong tidak terjadinya kesalahpahaman antar pengguna lain.

(2) Penyamaan Identitas Keagamaan dengan

Identitas Suku atau bangsa

Identitas menurut Stella Ting Toomey merupakan sebuah cerminan diri atau refleksi diriyang berasal darikeluarga, gender, budaya, etnis dan proses sosialisasi. Sebuah refleksi atas diri maka bisa dikatakan bahwa diri tidak bersifat statis atau terisolasi, melainkan diri sangat bergantung pada reaksi dan respon 
orang lain. Ketika orang lain menyatakan anda 'sangat Jawa', maka anda akan membuat diri anda dengan pernyataan yang diberikan oleh orang tersebut. Diri sebagai identitas akan memperlihatkan banyak gambaran karena hasil dari proses interaksi, baik itu identitas gender, identitas agama, maupun identitas nasional atau kebangsaan.

Pada percakapan yang terjadi di media sosial Facebook pada pemberitaaan tentang Paus mencium kaki orang muslim, maka identitas yang melekat sebelumnya tentang agama dikaitkan dengan identitas kebangsaan.

Pertentangan yang tajam antara individu yang berbeda cara pandang tentang keyakinan sehingga mendorong terjadinya kebencian akan sebuah suku bangsa tertentu. Kebencian tersebut yang mendorong 'menyamakan' suku bangsa tertentu dengan kondisi yang sifatnya negatif. Seperti pernyataan di bawah ini :

“ ayo ... onta onta ... neh kaki saya ... ayo ciumi ! hahaha ... geblek tenan ..."

"udahah, enthe jualan farfum sana ... jgn lupa bawa fentung buat buat jaga2 klw ada maksiat, langsung deh fentung fentung"

"budaya arab kan yg suka koar2 aurat wkwkwkwk ...."

"ketahuan budaya arab itu ngajarin laki jadi gampang ngaceng wkwkwkwkw .... Tkw tuh pada diperkosa tuannya"

"hahaha ini orang yg kerasukan ajaran arab ada yg mencak2"

"hahahaha di bali mana ada pemerkosaan ? Padahal banyak bule sliweran pake bikini. Coba klo arab"

Pernyataan tersebut memberikan gambaran bahwa percakapan mengenai suatu konteks beralih menjadi tindakan 'pencederaan' terhadap sebuah identitas kebangsaan bahkan kebencian terhadap suku bangsa tersebut. Pencederaan terhadap identitas itu diperlihatkan dengan penggunaan kata-kata yang bukan hanya sarkasme, seperti kerasukan ajaran araba tau kata seperti ketahuan budaya arab itu ngajarin laki jadi gampang ngaceng dan diakhiri dengan tertawa yang melecehkan $w k w k w k w k w$, tetapi sudah penghancuran identitas dan penghinaan yang terkesan di luar kendali. Ini memperlihatkan bahwa control terhadap diri dalam sebuah percakapan tidak berjalan dengan baik sehingga bisa dikatakan bahwa peningkatan suatu hubungan tidak akan berjalan dengan kualitas yang baik.

(3) Ketidakpercayaan terhadap berita yang disampaikan

Suatu pemberitaan bukan saja menyajikan isi yang faktual tetapi juga actual dan tidak membohongi publik. Namun dalam percakapan di media sosial Facebook, ada juga pengguna yang mempertanyakan tentang keabsahan suatu berita tersebut. Misalnya pernyataan seperti di bawah ini :

"HOAX"

"Berita aslinya dari Times Dan itu bkn abal2 ky kbnyakan media di Indonesia bro ..."

"nonton tv brooooo .... biar ngak kliatan begonya elo ...."

"emang kalo nonton tv lantas loh jadi pinter? Banyak berita hoax di tv, bego ! “

"pake akal sehat kala lihat dan baca berita"

Pernyataan tersebut memperlihatkan bahwa terjadi pergeseran makna dari yang coba dimainkan oleh pengguna sehingga 
mengurangi makna dari pemberitaan yang ditampilkan atau dengan kata lain mencoba membuat khalayak tidak mempercayai pemberitaan yang ditampilkan. Ketidakpercayaan terhadap berita yang ditampilkan mendorong terciptanya bias makna dan pada akhirnya pembuat berita di media sosial Facebook tidak dipercaya. Namun, ketika pemberitaan coba dibiaskan dari persepsi khalayak, terjadi reaksi yang seakan memperkuat kebenaran pemberitaan dengan meletakkan nama dari organisasi pemberitaan yang sudah dikenal dan layak dipercaya yakni TIMES. Dalam pembicaraan tersebut dapat terlihat bahwa hubungan tidak dibina dalam sebuah konstruksi bersama, tetapi perbincangan merupakan sebuah makna bagi diri sendiri (personal meaning).

(4) Egoisentrisme Agama

Egoisentrisme menunjukkan bahwa kebenaran suatu keyakinan merujuk pada keyakinan yang diyakini oleh individu itu sendiri. Pada percakapan yang terjadi terkait pemberitaan Paus mencium kaki, pengguna berusaha untuk mempertahankan keyakinan agamanya sebagai keyakinan yang paling benar dan sah sedangkan keyakinan orang lain adalah tidak benar bahkan mendegradasikannya sebagai kafir. Kafir menurut Wikipedia dikatakan sebagai 'orang yang menolak Allah, atau orang yang bersembunyi, menolak atau menutup dari kebenaran akan agama Islam". Pernyataan yang memperlihatkan hal ini dapat tergambarkan seperti dibawah ini :

"kalau dia benar2 muslim yang taat, pasti tidak mau dicium kakinya ...hah modus ..."
“... tapi peraturan dalam Islam itu tidak boleh di cium kakinya oleh hidung paus yang najis karena kaki kita orang islam sudah disucikan $5 \mathrm{x}$ sehari loh “

"hai orang-orang yang beriman, sesungguhnya orang-orang yang musyrik itu najis (QS At Taubah : 28)

"bagi yang muslim : bagimu Agamamu bagiku agamaku. Tidak mengikuti ritual agama di luar islam agar tidak mendistori aqidah yg diyakini”"

Pernyataan tersebut mengindikasikan seakan ada pemikiran bahwa keyakinan yang dimiliki oleh seseorang adalah keyakinan yang paling baik dan cenderung menyerang keyakinan padahal pemberitaan yang dilakukan bukan berbicara tentang agama tetapi berbicara tentang persaudaraan dalam kemanusiaan.

\section{Simpulan}

Penelitian ini menggambarkan model alur percakapan yang terjadi dikaitkan dengan hubungan antarpribadi. Individu merasakan hubungan antarpribadi yang bertujuan untuk mencapai kualitas kehidupan yang lebih baik. Kualitas kehidupan yang lebih baik menurut Stewart adalah membentuk suatu hubungan perkawanan yang lebih antara satu orang dengan orang lain atau dengan kata lain beralih dari impersonal menjadi interpersonal. Percakapan yang terjadi cenderung mengarah kepada destruktif bahkan menyerang identitas seseorang ataupun meragukan seseorang itu sebagai seseorang yang unik, khusus, dan sebagai makhluk ciptaan Tuhan.

Keberadaan media sosial seharusnya dipergunakan untuk memperkuat hubungan atau mencari hubungan dengan orang lain. Arah hubungan dari nonintimate menjadi intimate tidak terjadi dengan baik. Individu 
cenderung seenaknya dalam mengeluarkan pernyataan tanpa mempedulikan apakah pernyataan tersebut adalah pernyataan yang mendorong individu untuk belajar atau mendapat informasi dan pengetahuan dari pemikirannya. Mereka bahkan menyerang, melecehkan atau mencederai identitas yang sudah dimiliki oleh seseorang. Ini menandakan adanya kelemahan individu dalam literasi menggunakan media sosial itu sendiri. Substansi dari penelitian ini adalah pembelajaran bagi individu mengenai penggunaan media sosial sebagai media untuk berhubungan antarindividu. Model komunikasi antarpribadi melalui media sosial yang beretika sangat mendukung komunikasi yang harmonis.

\section{Daftar Pustaka}

Adler, R.B., \& Proctor, R.F. (2012). Looking Out Looking In (14 ${ }^{\text {th }} \mathrm{Ed}$.). Wadsworth, Cengage Learning.

Stewart, John. (2009). Bridges Not Walls : A book about Interpersonal Communication, $10^{\text {th }}$ edition. USA: McGraw Hills.

Turkle, Sherry. (2011). Alone together : why we expect more than technology and less from each other. New York

(2015). Reclaiming Conversation : The Power of Talk in a digital age. New York: Penguien Press.

West, Richard, Turner, Lynn H. (2014). Introduction Communication Theory : Analysis and Application. New York: McGraw Hill 